\title{
Home Telehealth and The Triple Aim
}

Joel J. Reich, MD

Thomas F. Osborne, MD

Authors' note: The Triple Aim is a framework developed to increase the value of healthcare through three interrelated components; improving the individual experience of care, improving the health of populations, and reducing the per capita cost of care for populations. Achieving the goals of the Triple Aim for everyone requires a fundamental change in how we deliver healthcare. A thoughtfully implemented home telehealth program has the potential to achieve these important endpoints for a large group of patients. However, its success is dependent upon numerous factors ranging from effective integration of technology and adoption to reimbursement policy.

Rising U.S. healthcare costs are placing an unsustainable strain on employers, government, and individuals. This financial burden is expected to escalate as people are living longer with chronic health conditions. At the same time, patients are demanding a greater level of value, convenience, and participation in their healthcare. In response to these pressures the U.S. healthcare system is undergoing unprecedented transformation. Payment reform is moving from fee-for-service to value-based reimbursement and technological advancements combined with operational changes are facilitating a transition from institutional care settings such as the hospital to less formal settings including the home. 1

Creating effective, less costly, patient-centered alternatives requires redesign of many fundamental aspects of healthcare delivery. Home telehealth programs hold great promise in facilitating this critical paradigm shift in healthcare. Success depends on interrelated factors, which are well illustrated in the context of the Triple Aim.

\section{The Triple Aim}

The "Triple Aim" is a framework developed for improved population health (Figure 1). This ambitious strategy was developed by the Institute for Healthcare Improvement (IHI) a decade ago in its effort to redesign the U.S. healthcare system. As stated by Dr. Donald Berwick, the former President \& CEO of IHI, “... the United States will not achieve high-value healthcare unless improvement initiatives pursue a broader system of linked goals. In the aggregate, we 
call those goals the "Triple Aim": improving the individual experience of care; improving the health of populations; and reducing the per capita costs of care for populations." ${ }^{2}$

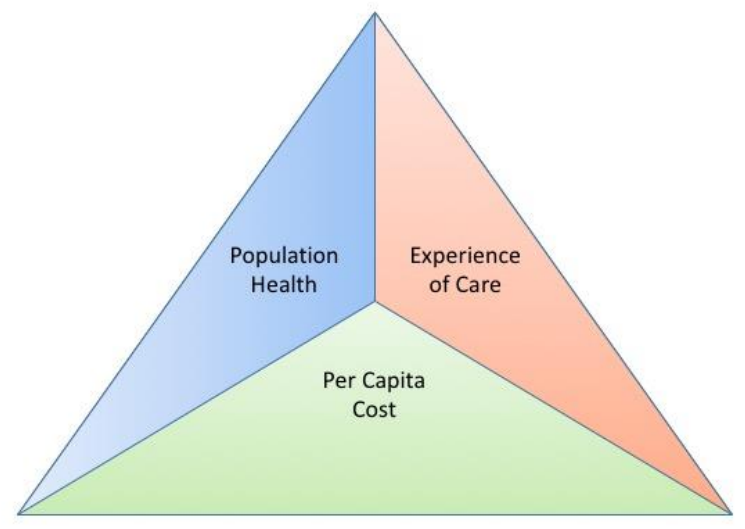

Figure 1. The Triple Aim http://www.ihi.org/engage/initiatives/tripleaim/pages/default.aspx

Triple Aim implementation began in 2007 with a group of 15 organizations in the U.S., England, and Sweden and was quickly adopted by The Centers for Medicare and Medicaid Services (CMS) during Berwick's short tenure as Administrator. The goals have subsequently become the "mantra" of healthcare reform, with adoption of the aims by many healthcare systems and accountable care organizations. As a result, in 2014, more than 150 organizations across the world participated in efforts to achieve these aims. $\frac{3}{}$

In recognition of the high degree of interdependence, the intent of the Triple Aim is to achieve the three linked goals simultaneously. However, the synchronized achievement of these interrelated measures is complex and challenging. The required redesign of healthcare financial, clinical, and operational relationships underscores that these goals will not be achieved with minor modifications to the status quo. However, for simplification of discussion, the following sections will consider each component of the Triple Aim individually in relation to how it relates to home telehealth.

\section{Improving the Individual Experience of Care}

Home telehealth may improve the experience of care in various ways. For many, the familiar comfort and convenience of one's own home is much more appealing than a healthcare facility and therefore it is not surprising that there is a growing vocal trend among seniors and baby boomer, soon-to-be seniors, who prefer this option. $\underline{4, \underline{5}, 6}$ Home healthcare services are also 
essential for those who are homebound and are of great value to those for whom the logistics of traveling to a doctor's office is a tremendous burden. In addition, due to frailty or functional limitation, many would benefit from the added safety of digital monitoring in the home or in nonmedical residential institutions such as assisted living facilities. As a result, a technologyenabled home health system can prolong independence and one's control of the context.

User acceptance is a foundational component to achieving a positive home telehealth care experience and begins with selecting appropriate patients who are comfortable using the specific technology. ${ }^{7}$ The. technology components of home telehealth, including glucometers, oximeters, and digital scales, have been available for many years as standalone devices. Historically, data collection and reporting has for the most part been manual, often in the form of patient-generated handwritten records, which are then carried to the care provider at the time of office visits. Advances in wireless device technology, increased accessibility to broadband networks, and integration, have significantly advanced the capability to report, aggregate, and share the biometric data with care provider teams to enable timely data analysis and response times.

Acceptance and endorsement from members of the care team is a sometimes neglected but critical feature for success. $\stackrel{-}{ }$ On a similar note, engagement of appropriately designated family and friends is also a key factor for an improved healthcare experience. This is particularly true for friends and family of patients who are chronically ill, disabled, or elderly because they are likely to be involved in each stage of home telehealth implementation. Therefore, measures to incorporate all of these collaborators in the enrollment, setup, management, and troubleshooting of home telehealth solutions should not be overlooked. Failure to properly address each of these stakeholders may result in dissatisfaction and the perception that technology has become a substitute rather than an enhancer of the team relationship. $\underline{9}$

Improved acceptance and experience from each collaborator can be achieved with a thoughtful approach to the overall design of the program and selection of the appropriate technological tools. However, balancing a technology's utility with usability can be challenging. ${ }^{10}$ For example, design considerations for older patients should include providing tools and interfaces that take into account common issues such as potential vision, cognitive, and dexterity limitations. 
Special care and attention must also be given to the workflow and needs of care providers. Home telehealth functions best when it is integrated into the established care process and information systems. ${ }^{11}$ Regrettably, many home telehealth programs are free-standing and not interoperable with health system EHRs (electronic health records), which is a significant impairment to success. ${ }^{8}$ If the home telehealth program becomes intrusive due to poorly designed technology or workflow the resulting decreased provider efficiency will make it virtually impossible to obtain the necessary support and participation for effective adoption. When technological tools are developed without the direct consultation or understanding of a healthcare provider's perspectives, the results are typically suboptimal. For example, a wellintended tool may have negative consequences such as overly aggressive alert thresholds resulting in disruptive false alarms that consume valuable time when staff responds to a nonevent, or, at the other extreme, delayed (or nonexistent) response, with the potential for negative outcomes due to real events missed. With either scenario, cost of care increases without obvious purpose. ${ }^{12}$ Similarly, a primary care physician may derive considerable value from an organized once per month summary of glucose measurements, however, delivery of daily or hourly noncritical results may quickly lead to frustration. As with all other health information technology systems, privacy, data security, interoperability, data aggregation, and technical support are essential for sustainability.

Home telehealth also has the potential to significantly enhance the experience of care through both healthcare provider and social connections. These benefits include, but are not limited to, creating a direct connection to care providers, friends, and family as well as providing a sense of security via appropriate electronic safety alerts. The potential benefits of dampening the social isolation experienced by many who are chronically ill, as well as empowerment of selfmanagement and independence should not be understated. The overall improved home healthcare experiences that can be achieved in these situations is reflected in the high patient satisfaction scores reported by patients within the Veterans Health Administration system and others. $\underline{8}, \underline{9}, \underline{13}$

\section{Improving the Health of Populations}

While there are many methodologies for defining populations and data, ultimately patients are stratified into groups to enable the most beneficial assignment of resources to define and manage needs. Depending on the perspectives, populations may be defined by criteria such as disease type, severity scoring, source of payment, and geography. Patient stratification, often 
illustrated with a pyramid, is used to illustrate progressively more intense care services required; beginning at the low risk group that is well-served by wellness programs, the moderate risk group with coaching and self-care/management, high risk group with disease management, and the very high risk group with the addition of case management. Individuals with one or more chronic diseases in the moderate risk, high risk and noninstitutionalized very high risk groups derive the greatest clinical value from home telehealth(Figure 2) 14

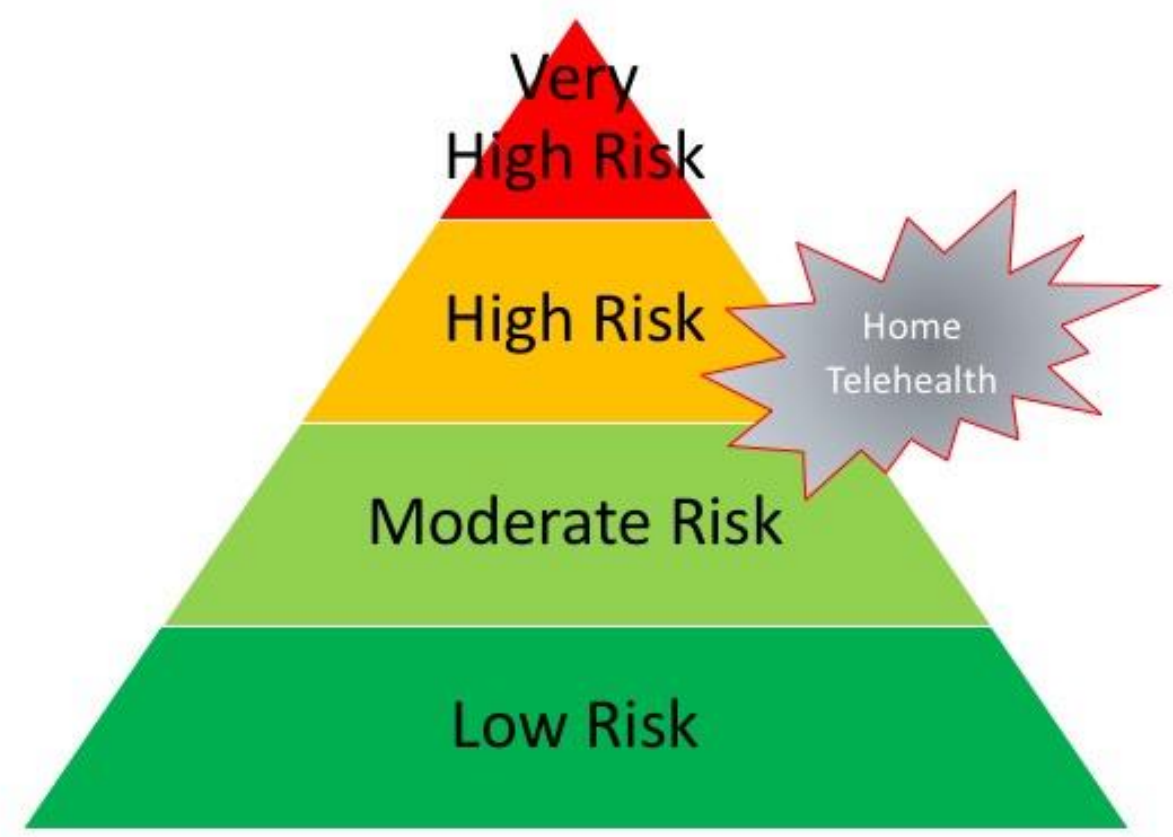

Figure 2. Population health stratification

The ultimate goal of population health is to define the population's health needs and disparities, identify the individuals who have these needs, and address the needs through care management and clinical services.

Research from the past decade has shown mixed results regarding the value, return-oninvestment, and efficacy of home telehealth programs. There are many variables to consider and therefore these studies need to be thoughtfully evaluated in the context of the specific program, patient population, and methodology. An additional challenge in the evaluation of home telehealth programs is applying research findings from studies of a single disease entity to patients in the high and moderate severity population who often have multiple diseases. As a result, the limited scope of many research studies leaves unanswered questions regarding the full potential of home telehealth for more complex patients. $\frac{15}{}$ 
Meaningful evaluation is also confounded by the difficulty in obtaining complete follow-up data when multiple sites of care (hospitals, physician offices, labs) are utilized in unrelated health systems without interoperable data systems. $\stackrel{-}{-}$ Therefore, critical considerations include factors such as the degree of network development, leadership, care provider support for home telehealth, and the extent of clinical integration at the time of the study. $\underline{16}, \underline{17}$ It is becoming clear that a successful-home telehealth program needs to be well-integrated into a system, which includes linked home health, disease management, transitional care, and primary care services.11 Without these components and a well-constructed response plan, its full value will not be realized. - By example, favorable results for home telehealth have been reported by wellorganized integrated programs including the Veterans Health Administration, Banner Health, and Geisinger Health System. $\underline{8}, \underline{18}, \underline{19}$

\section{Reducing Per Capita Costs of Care for Populations}

Staggering healthcare costs across virtually all patient populations have far reaching implications to our economy and society. In response to this, government payors (i.e., Medicare and Medicaid) and commercial insurance companies (including employer self-funded health insurance) are shifting financial risk to healthcare systems and physicians through shared savings, bundled payment, and capitation programs. There are many variations in these plans; however, they all share the common goal of replacing more expensive care with improved primary care, care management, preventative medicine, and other safe alternatives. $\underline{20}$ [Frakt]

The goal of efficiently lowering healthcare costs is particularly important for our growing senior population, who are living longer with multiple chronic conditions, functional impairment, frailty and social stressors. This dilemma is especially problematic because this population already accounts for half of the costliest $5 \%$ of patients. ${ }^{21}$ Multiple federal cost saving measures are being initiated to meet this challenge. While there are many views on how to most effectively reduce healthcare spending, considerable effort is presently focused on reducing acute hospital care and home telehealth is well positioned to be an important part of the solution.

In addition, CMS rating programs, as well as those implemented by private insurance companies, use readmission as a key metric for determining rewards and penalties. This has become increasingly important because with shortened hospitalization, patients, particularly the elderly, may leave the hospital before being completely stable and without a thorough 
understanding of diet and medication discharge instructions. In addition, these patients are also more vulnerable and in greater need of support to make the transition safer and to avoid readmission. $\underline{22}$ When combined with organized residential safety assessments, a specifically designed and technologically enabled, home telehealth program can bridge this critical gap. When successfully implemented, a well-integrated system can identify early status changes for the conditions contributing the most to hospitalization and re-hospitalization such as heart failure, COPD/pneumonia, diabetes and the myriad complications of diabetes. A common example is weight gain by a heart failure patient. Early identification of the change in status can lead to timely intervention and management at home or at the primary care physician's office, therefore avoiding an expensive emergency department and/or hospital admission $\underline{23}$

In our dynamically changing reimbursement system calculating exactly where the cost savings occur, and to whom they accrue is challenging. In the traditional fee-for-service system, reduced hospital admissions decrease a health system's revenue and therefore this lack of alignment has been a source of federal policy changes. On the other hand, in a physician-only shared savings program, a physician group may be financially rewarded for reducing hospital admissions. Likewise, the cost to the insurer is also reduced when hospital admissions is avoided. In a value-based system with risk-sharing, the expense to create the infrastructure that results in the savings may occur in different areas of the network. For example, a home health provider may run the home telehealth program with payment from direct monthly fees or a grant, yet the savings on reduced expenses such as acute hospitalizations may benefit a local independent Accountable Care Organization or clinically integrated network. $\underline{11}$ 논 $\underline{24}$. Similarly, remote management of chronic diseases in partnership with a primary care provider may also reduce expenditures for specialist care and lab testing. Furthermore, preventive care measures provided electronically in the home, including wellness education and activity monitoring via wearable technology, may result in cost savings to multiple different entities.

While system level cost reduction efforts have considerable importance, those accrued to individuals, families, and groups that compose the populations is a critical component of system transformation's success or failure. It is difficult to place a dollar value on improved personal health and quality of life; however, there are some variables that can be calculated directly, including fewer absences from work, reduced out-of-pocket expenditures on emergency department and acute hospitalization costs, as well as the associated transportation costs. 
As part of an effort to increase value, in both the fee-for-service system and the value-based payment systems, CMS and private insurance programs allocate both direct financial rewards and penalties based on patient experience scores. Poor patient and family experience also places considerable fee-for-service revenue at risk due to damaged institutional reputation and decreased referral rates. Because a successfully implemented home telehealth program contributes positively to patient and family experience, it therefore results in financial benefit to the care provider in many ways regardless of the payment model.

As value-based payment and accountable care arrangements mature and grow, the true benefits of home telehealth may be more fully realized. Overall, however, attainment of the Triple Aim may require substantial reallocation of healthcare resources from traditional fee-forservice payment arrangements to clinically integrated "value-based" payment models.

\section{Conclusion}

The Triple Aim is an increasingly popular framework that can be utilized to achieve the goals of improved healthcare. A successfully implemented home telehealth program is well positioned to achieve the interrelated objectives of improved health, as well as enhancing the experience of care at a lower cost. As health networks grow in sophistication, size, and scope, the true value of home telehealth will be realized. While reimbursement models are lagging behind program deployment, there is growing evidence that home telehealth solutions, appropriately integrated with traditional healthcare programs, will positively contribute to our developing value-based healthcare system.

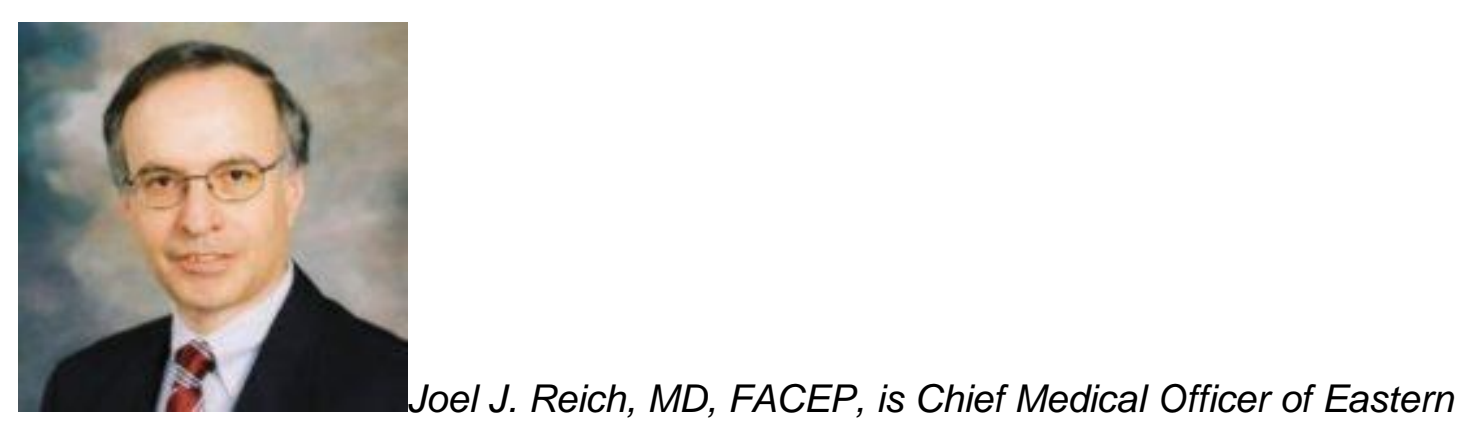

Connecticut Health Network. 


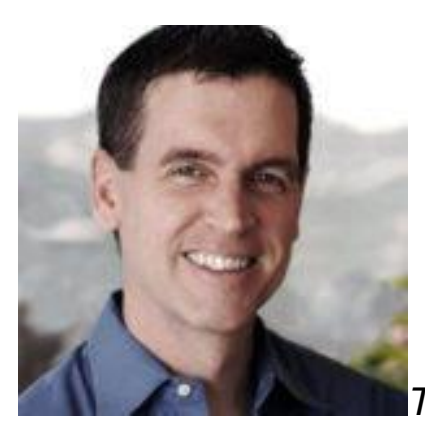

Thomas F. Osborne, MD, is Director of Medical Informatics at vRad (Virtual Radiologic), the leading teleradiology services and telemedicine company, which leverages its proprietary technology, data, and analytics capabilities to rapidly move patient images and information across a secure global network of 2,100 medical facilities in all 50 states.

Dr. Osborne conceived the idea for this series of articles. He, and Dr. Reich contributed to the content of this article.

\section{References}

1. Osborne TF, Reich JJ, Arkwrite MHA, Russo, Jr, J. On the digital road to home healthcare. Telehealth and Medicine Today. 2016 August 1(3). URL:

http://www.telhealthandmedtoday.com/on-the-digital-road-to-improved-homehealthcare/. Accessed 9/20/16.

2. Berwick DM, Nolan TW, Whittington J. The Triple Aim: Care, health, and cost. Health Affairs. 2008;27(3):759-769. doi:10.1377/hlthaff.27.3.759.

3. Case J. A Primer on defining the Triple Aim. Blog by Jameson Case. Friday, October 17, 2014. URL:

http://www.ihi.org/communities/blogs/ layouts/ihi/community/blog/itemview.aspx?Li

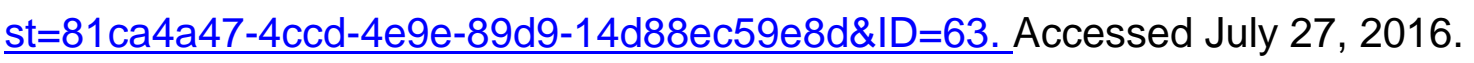

4. Accenture. Tech-savvy seniors want online options to access care from home, Accenture survey shows.URL: https://newsroom. accenture.com/industries/healthpublic-service/tech-savvy-seniors-want-online-options-to-access-care-from-homeaccenture-survey-shows.htm. Accessed August 5, 2016.

5. National Institute on Aging. There's no place like home-for growing old. URL: https://www.nia.nih.gov/health/publication/theres-no-place-home-growing-old. Accessed August 5, 2016. 
6. Family Caregiver Alliance. Selected long-term care statistics. 2015. URL:

https://www.caregiver.org/selected-long-term-care-statistics Accessed August 11, 2016.

7. Viers BR, Pruthi S, Rivera ME, et al. Are patients willing to engage in telemedicine for their care: A survey of preuse perceptions and acceptance of remote video visits in a urological patient population. Urology. 2015;85(6):1233-1240. doi:10.1016/j.urology.2014.12.064.

8. NORC at the University of Chicago. Health IT and health disparities: Patient provider telehealth network-using telehealth to improve chronic disease management. 2012. URL:

https://www.healthit.gov/sites/default/files/pdf/RCCHCandPHS CaseStudy.pdf. Accessed July 10, 2016.

9. Broderick A, Lindeman D. Case studies in telehealth adoption. The Commonwealth Fund; 2013. URL:

http://www.commonwealthfund.org/ /media/Files/Publications/Case\%20Study/2013 /Jan/1654 Broderick telehealth adoption synthesis.pdf. Accessed July 10, 2016.

10. Chau PYK, Hu PJH. Investigating healthcare professionals' decisions to accept telemedicine technology: an empirical test of competing theories. Inform Manage. 2000;39:297-311.

12. Murias G, Sales B, Garcia-Esquirol O, Blanch L. Telemedicine in critical care. Open Respir Med J. 2009 Mar 12;3:10-6. doi: 10.2174/1874306400903010010.

11. Singh R, Mathiassen L, Stachura ME, Astapova EV. Dynamic capabilities in home health: IT-enabled transformation of post-acute care. JAMIA. 2011;12:163-188.

13. Jimison $\mathrm{H}$, Gorman $\mathrm{P}$, Woods $\mathrm{S}$, et al. Barriers and drivers of health information technology use by the elderly chronically ill and underserved. AHRQ Publication No. 09-E004. 2008. URL:

http://www.ahrq.gov/downloads/pub/evidence/pdf/hitbarriers/hitbar.pdf. Accessed July 10, 2016.

14. Munro D. Targeting the 'superusers' of healthcare with telehealth. Forbes. May 2015. http://www.forbes.com/sites/danmunro/2015/05/03/targeting-the-superusersof-healthcare-with-telehealth/\#3296cb6d5dd3. Accessed August 5, 2016. 
15. Denesen B, Nonnecke B, Lindeman D, et al. Personalized health in the future: A global research agenda. J Med Internet Res. 2016;18(3):e53.

16. Ekeland AG, Bowes A, Flottorp S. Effectiveness of telemedicine: a systematic review of reviews. Int J Med Inform. 2010;79(11):736-771.

17. Mushcab H, Kernohan WG, Wallace J, Martin S. Web-based remote monitoring systems for self-managing type 2 diabetes: A systematic review. Diabetes Technol Ther. 2015;17(7):498-509.

18. Dahl D, Reisetter JA, Zismann N. People, technology, and process meet the Triple Aim. Nurs Admin Q. 2014;38(1):13-21.

19. Maeng DD, Starr AE, Tomcavage JF, Sciandra J, Salek D, Griffith D. Popul Health Manag. 2014;17(6):340-344.

20. Frakt $A B$, Mayes R. Beyond capitation: How new payment experiments seek to find the 'sweet spot' in amount of risk providers and payers bear. Health Affairs. 2012;31(9):1951-1958. doi:10.1377/hlthaff.2012.0344.

21. Leff B, Carlson CM, Saliba D, Ritchie C. The invisible homebound: Setting qualityof-care standards for home-bound primary and palliative care. Health Aff. 2014;34(1):21-29.

22. Nguyen OK, Makam AN, Clark C, et al. Vital signs are still vital: Instability on discharge and the risk of post-discharge adverse outcomes. J Gen Intern Med. August 2016. doi:10.1007/s11606-016-3826-8.

23. Silow-Carroll S, Edwards JN, Lashbrook A. Reducing hospital readmissions: Lessons from top-performing hospitals. The Commonwealth Fund. 2011 April $6^{\text {th }}$. URL: http://www.commonwealthfund.org/publications/casestudies/2011/apr/reducing-hospital-readmissions. Accessed 9/20/16.

24. Davis C, Bender M, Smith T, Broad J. Feasibility and acute care utilization outcomes of a post-acute transitional telemonitoring program for underserved chronic disease patients. Telemed J E Health. 2015;21(9):705-713. 